\title{
O CURSO DE PEDAGOGIA DA FURG CONSTITUINDO DIFERENTES SENTIMENTOS DE PERTENCIMENTO
}

\author{
Suzane da Rocha Vieira ${ }^{1}$ \\ Cleuza Maria Sobral Dias ${ }^{2}$ \\ Vanise dos Santos Gomes ${ }^{3}$ \\ Universidade Federal do Rio Grande - FURG
}

\section{RESUMO}

O presente trabalho discute a trajetória do curso de Pedagogia da Universidade Federal do Rio Grande - FURG, verificando as modificações pelas quais o curso e a universidade passaram nos últimos anos, face a aprovação das Diretrizes Curriculares Nacionais para o curso de Pedagogia. O Projeto Político-Pedagógico do Curso de Pedagogia-Licenciatura é analisado destacando seus objetivos, intencionalidades, bem como a organização curricular com o propósito de destacar as principais mudanças ocorridas no currículo do curso, considerando o fim das habitações e sua implicação na identificação dos estudantes com o curso, no perfil do egresso do curso, e, nesse processo, instituindo diferentes sentimentos de pertencimento ao curso. Por fim, verificou-se que o oferecido pela FURG atende a legislação vigente, apresentando um currículo bastante generalista, focado na formação de professores para Educação Infantil e anos iniciais do Ensino Fundamental e possui a docência como eixo central da formação.

Palavras-chave: Curso de Pedagogia; Diretrizes Curriculares; Pedagogo

\section{THE COURSE OF EDUCATION OF BECOMING DIFFERENT FURG FEELINGS OF BELONGING}

\begin{abstract}
This work argues the history about the Pedagogy course in University Federal of Rio Grande - FURG, considering the modifications that the course and the university undergo in the last years, also considering the new National Curricular Guidelines to the Pedagogy course. The Pedagogic-Politic Project of the Course of Bachelor Degree on Pedagogy is analyzed highlighting its goals, intentionality, as the curricular organization detaching the main changes on the course curriculum, considering the end of habilitations and the implications on the students identifications with the course, on the egress profile, and, on this process, establishing the sense of belonging to the course. Finally, it was verified that the course offered on FURG attend the current legislation, presenting a generalist curriculum, considering mainly the teachers formations on Childhood Education and Fundamental Teaching and has the teaching as formation central axis.
\end{abstract}

Keywords: Pedagogy Courses; Curricular Guidelines; Pedagogue

Introdução

O Curso de Pedagogia da Universidade Federal do Rio Grande - FURG, desde sua criação em 1961, passou por várias organizações curriculares que foram definindo diferentes perfis de pedagogo, e, nesse processo, instituindo diferentes sentimentos de pertencimento ao curso. Desde 2007, devido à aprovação das Diretrizes Curriculares Nacionais para o Curso de Pedagogia, a FURG passou a oferecer o Curso Pedagogia- 
Licenciatura. Com a nova organização curricular, os cursos de Pedagogia - Educação Infantil e Pedagogia - anos iniciais do Ensino Fundamental foram extintos, e esse aspecto segundo a coordenação do curso na universidade representa a alteração mais radical que o curso sofreu.

Assim, neste trabalho buscamos compreender a trajetória do Curso de Pedagogia na FURG desde sua criação, verificando as mudanças pelas quais o curso e a universidade passaram nos últimos anos. Na sequência, analisamos o Projeto Político-Pedagógico do Curso de Pedagogia-Licenciatura, destacando seus objetivos, intencionalidades, bem como a organização curricular a fim de evidenciar as mudanças sofridas pelo currículo do curso, considerando o fim das habitações e sua implicação na identificação dos estudantes com o curso.

Para realizar a análise dos documentos nos orientamos pela proposta teóricometodológica sugerida por Shiroma, Campos e Garcia (2005), a qual indica a necessidade de um estudo aprofundado sobre quais conceitos e argumentos são privilegiados e quais os intencionalmente "desprezados" nos textos do corpus documental. Para as autoras, esse processo nos aproxima da lógica ou racionalidade que sustenta os documentos. Cabe lembrar que os conceitos são muito importantes, pois, dependendo do contexto, as palavras podem adquirir significados diferentes, e a forma como os conceitos são utilizados nas políticas públicas na maioria das vezes contribuem para a construção de uma "hegemonia discursiva", provocada pela disseminação massiva de documentos oficiais.

Desse modo, todos os documentos foram estudados no sentido de compreender quais são seus conceitos principais e de que forma eles aparecem nos diversos documentos. Para isso foi preciso desconstruir os textos e compreender a intertextualidade dos documentos, tendo em vista que

a "desconstrução" dos textos visando à compreensão de seu processo de produção torna-se um importante mecanismo de análise discursiva, na medida em que permite localizar as inconsistências dos textos, os pontos em que transgride os limites dentro dos quais foi construído (SHIROMA; CAMPOS; GARCIA, 2005, p.433).

Ao realizar a análise da trajetória e do atual currículo do curso de Pedagogia da FURG, consideramos que as políticas educacionais não podem ser compreendidas como processos unidirecionais e lineares. Portanto, procuramos olhar para nosso objeto de estudo a partir do entendimento que as políticas públicas, ao serem colocados em prática, são modificados e reinventadas pelos sujeitos.

\section{O CURSO DE PEDAGOGIA NA FURG}

A história do Curso de Pedagogia na FURG passa pela própria história da Universidade, que foi fundada em 1969 e tem sua trajetória marcada por um movimento cultural da comunidade rio-grandina, ${ }^{4}$ que se empenhou para a criação de escolas de ensino superior no município a partir da década de 1950. O contexto da época revelava uma carência de cursos superiores, fato que levava os jovens a se dirigirem para outras regiões em busca de estudos e não regressarem ao município do Rio Grande.

Tendo em vista essa realidade e considerando o parque industrial que existia no município na época, em 1951 um grupo de empresários liderado pelo Engenheiro Francisco Martins Bastos reuniu-se para discutir a criação de um curso superior na cidade. Assim, deu-se início ao processo de criação da primeira faculdade no município, conhecida como Escola de Engenharia Industrial ${ }^{5}$. Sendo necessário que a referida escola tivesse uma mantenedora, conforme exigido pelo Ministério da Educação e Cultura, em 8 de julho de 
1953, foi instituída a Fundação Cidade do Rio Grande, que posteriormente passou a ser a Universidade Federal do Rio Grande -FURG (ALMEIDA, 2004).

Após a criação da Escola de Engenharia Industrial, outras faculdades surgiram na cidade, preocupadas também em atender a uma demanda social da região e articuladas aos propósitos da Fundação Cidade do Rio Grande. Assim, por iniciativa do poder público municipal, em 22 de junho de 1955 foi criada a Faculdade de Ciências Políticas e Econômicas ${ }^{6}$. Na esteira do movimento pró-ensino superior vivido pelo município, em 1959 houve uma mobilização para instalar em Rio Grande uma Faculdade de Direito, a ser mantida pela Mitra Diocesana de Pelotas através da Universidade Católica ${ }^{7}$. Assim, em 2 de fevereiro de 1960, pelo Decreto 47.738, foi autorizado o funcionamento da instituição, que recebeu o nome de Faculdade de Direito "Clóvis Beviláqua" (NUNES, 2004).

O vinculo estabelecido com o município vizinho de Pelotas propiciou que novos cursos pudessem ser instalados em Rio Grande, atendendo às expectativas da comunidade com o acesso ao ensino superior. Portanto, em 1960, a Mitra Diocesana de Pelotas propõe a criação da Faculdade Católica de Filosofia de Rio Grande, inicialmente com a oferta dos cursos de Filosofia e Pedagogia e posteriormente os cursos de Línguas ${ }^{8}$, Matemática ${ }^{9}$, Ciências e Estudos Sociais ${ }^{10}$. Os cursos de Filosofia e Pedagogia foram autorizados para funcionar em janeiro de 1961, por meio do Decreto ${ }^{\circ} 49.963$.

Sobre a Faculdade de Filosofia, Alves destaca

\begin{abstract}
A Faculdade Católica de Filosofia de Rio Grande seguia a senda trilhada pelas demais instituições de ensino superior até então criadas nesta cidade e que culminaram com a criação da Fundação Universidade Federal do Rio Grande, ou seja, era fruto de esforços e mobilizações individuais e coletivas dos mais diversos segmentos da comunidade visando a dotar o município e a região de estabelecimentos educacionais que permitissem a formação técnica de profissionais e o aprimoramento cultural da população. No caso da Faculdade de Filosofia, ela marcava a gênese de vários cursos de licenciatura das mais diversas áreas do conhecimento humano, ou seja, Pedagogia, Filosofia, Letras, Matemática, Estudos Sociais e Ciências, os quais constituíram o embrião dos cursos que no futuro, já à época da FURG, viriam ser os responsáveis pela formação de professores. Aliás, esta foi a motivação precípua da Faculdade de Filosofia, preencher as lacunas existentes quanto ao quadro docente a atuar na comunidade rio-grandina e em sua zona de abrangência, bem como qualificar os professores que já atuavam nas redes pública e privada. $(2004$, p. $83-84)$
\end{abstract}

Conforme evidenciado, ao final dos anos de 1960, em Rio Grande já existia um expressivo número de cursos superiores. A Fundação Cidade do Rio Grande liderou a discussão acerca da criação de uma Universidade da zona sul do Estado no município. Em 20 de agosto de 1969 é autorizado o funcionamento da Universidade do Rio Grande pelo Decreto-Lei n ${ }^{\circ} 774$, assinado pelo então Presidente da República Arthur da Costa e Silva.

Almeida relata que esse Decreto-Lei

estabelece a Universidade como uma fundação de direito privado com autonomia didático-científica, administrativa, financeira e disciplinar constituída pelas unidades reconhecidas: Escola de Engenharia Industrial do Rio Grande (federal); Faculdade de Ciências Políticas e Econômicas do Rio Grande (municipal); Faculdade Católica de Filosofia do Rio Grande e Faculdade de Direito Clovis Beviláqua. Os estabelecimentos de ensino anteriormente citados 'passam a denominar-se, respectivamente, Faculdade Federal de Engenharia Industrial, Faculdade de Ciências 
Políticas e Econômicas e Faculdade de Filosofia, Ciências e Letras, mantida a denominação da Faculdade de Direito'. Ainda estabelece ' A Faculdade de Medicina do Rio Grande deverá integrar-se na Universidade do Rio Grande, assim que venha a ser legalmente reconhecida' (2004, p. 30).

Nesse processo de constituição da Universidade do Rio Grande, por meio do Decreto $\mathrm{n}^{\mathrm{o}} 65.462$ de 21 outubro de 1969, foi aprovado o Estatuto da Fundação Universidade do Rio Grande como entidade mantenedora da Universidade. Dezoito anos após a aprovação do funcionamento da Universidade do Rio Grande, em 1987 a FURG torna-se uma fundação pública, tendo seu funcionamento custeado por recursos da União Federal, passando a denominar-se Fundação Universidade Federal do Rio Grande - FURG. No ano de 2007, após passar por uma revisão da estrutura organizacional e do estatuto da Universidade, adotou o nome de Universidade Federal do Rio Grande - FURG.

Com esse breve histórico da FURG, procuramos evidenciar que o Curso de Pedagogia estava presente no momento da fundação da Universidade e que esse ocupava e ainda ocupa um importante papel no município, no que se refere à formação de professores.

Nos 43 anos da FURG, houve 26 propostas curriculares diferentes para cursos de Pedagogia, sendo quatro desenvolvidas no âmbito do Programa de Professores Leigos atendendo aos municípios de São José do Norte, Santa Vitória do Palmar, Santo Antônio da Patrulha e atualmente o município do Rio Grande. E quatro cursos oferecidos na modalidade a distância por meio do Sistema Universidade Aberta do Brasil, nos polos de Mostardas, Santa Vitória do Palmar, Santo Antônio da Patrulha e São José do Norte. Neste trabalho, iremos nos deter nas ofertas dos cursos de Pedagogia na modalidade presencial com oferta regular.

A formação oferecida pelo Curso de Pedagogia na FURG passou por diversas habilitações, entre elas a formação de professores para atuar nas matérias pedagógicas do Magistério $^{11}$, na pré-escola, na Educação Infantil, nos anos iniciais do Ensino Fundamental e pela formação de orientadores educacionais, supervisores educacionais, administradores educacionais e inspetores educacionais ${ }^{12}$. As modificações que foram ocorrendo no currículo do Curso de Pedagogia ao longo dos anos, não aconteceram de forma isolada, acompanharam as discussões nacionais acerca da formação do pedagogo. Cabe lembrar, que desde sua criação na década de 1930, o Curso de Pedagogia tem sido alvo de muitos debates que envolvem questões relacionadas à identidade do pedagogo, do seu papel social e das questões curriculares relacionadas ao seu processo de formação.

Inicialmente, o Curso de Pedagogia da FURG formava o especialista da Educação, habilitando para as áreas de Orientação Educacional, Supervisão Educacional, Administração Escolar e Inspeção Escolar articuladas com a formação para o Magistério das Matérias Pedagógicas do $2^{\circ}$ grau. Segundo estudo realizado, Ribes et ali (1995), o currículo destes cursos de Pedagogia eram extremamente generalistas e ainda permitiam aos egressos atuarem na docência de disciplinas de caráter bastante diferenciados como a Matemática ( $1^{\circ}$ e $2^{\circ}$ ciclo), a História ( $1^{\circ}$ e $2^{\circ}$ ciclo), a Sociologia, Filosofia, Psicologia e ainda em todas as disciplinas específicas do curso Normal.

Acompanhando todo o debate nacional, em 1983, na FURG foi aprovada pelo Conselho de Ensino, Pesquisa e Extensão da universidade a Resolução no 5/1983, que estabeleceu a extinção da oferta das habilitações Administração Escolar; Supervisão Escolar; Inspeção Escolar e Orientação Educacional, indicando que estas fossem oferecidas através de Cursos de Pós-Graduação, em Nível de Especialização. A Resolução ainda previa a criação de três novas habilitações Magistério para a Pré-Escola; Magistério 
para as Séries Inicias do Ensino de $1^{\circ}$ Grau e Magistério para a Educação Especial, sendo definidos que todas estas habilitações deveriam ser desenvolvidas concomitantemente com a Habilitação: Magistério das Matérias Pedagógicas do $2^{\circ}$ Grau. Assim, a partir de 1983, a FURG passou a oferecer o Curso de Pedagogia apenas com a habilitação Magistério das Matérias Pedagógicas do $2^{\circ}$ Grau. No mesmo período, na universidade deu inicio a um processo de estudos e discussão com a participação de docentes e discentes com o intuito de elaborar a proposta pedagógica para os novos cursos.

Cabe destacar que a extinção das habilitações de especialistas do Curso de Pedagogia da FURG, segundo Medeiros, ocorreu devido ao "excesso de pessoal formado sem aproveitamento, uma vez que não havia concurso específico para especialistas" e ainda "tempo reduzido para a formação conjunta do Professor das disciplinas pedagógicas do ensino de $2^{\circ}$ grau e do especialista"(1999, p.81).

A oferta do Curso de Pedagogia habilitação Magistério das Matérias Pedagógicas do $2^{\circ}$ Grau ocorreu até o ano de 1987, quando foi aprovada uma nova organização para o Curso de Pedagogia. A proposta pedagógica das novas habilitações foi aprovada pelo Conselho de Ensino, Pesquisa e Extensão em 1986, e regulamentada pela Deliberação no 17/1986. Assim, em 1988 passaram a funcionar na FURG as habilitações para as Séries Iniciais do $1^{\circ}$ Grau no turno da manhã e para a Pré-Escola no turno da noite, ficando a habilitação para o Magistério das Matérias Pedagógicas do $2^{\circ}$ Grau como apostilamento às novas habilitações.

A criação das duas novas habilitações foi justificada pela crescente demanda de professores por formação em nível superior para essas áreas e pela inexistência de cursos com formação específica para o magistério, nas Séries Inicias do $1^{\circ}$ Grau e na Pré-Escola, que acabavam procurando outros cursos e não mais se interessavam em continuar exercendo a docência nesses níveis de ensino. Na época, também se entendeu que a melhoria do ensino oferecido nas séries iniciais passava por uma formação mais direcionada às teorias e práticas que dão conta da alfabetização e dos conhecimentos desse nível de ensino.

A organização curricular dos dois cursos previa que fosse oferecida nos quatro primeiros semestres uma formação geral, a partir de disciplinas das áreas de Sociologia, História da Educação, Psicologia e Filosofia, as quais formariam um núcleo comum. E nos quatro últimos semestres, o currículo dos cursos apresentava características bastante diferenciadas, com disciplinas voltadas para a formação específica de cada área.

Para a habilitação Pré-Escola, a proposta previa que os estudos realizados nas disciplinas seriam direcionados para o trabalho com crianças entre 5 e 6 anos de idade. Da mesma forma, na habilitação Séries Iniciais do $1^{\circ} \mathrm{Grau}$, o foco estava no trabalho com crianças a partir dos 7 anos de idade. Para o apostilamento da habilitação do Magistério das Matérias Pedagógicas do $2^{\circ} \mathrm{Grau}$, os estudantes deveriam cursar em ambas as habilitações uma disciplina de Metodologia do Ensino de $2^{\circ}$ Grau e optar por realizar a disciplina de Prática de Ensino em Escola de $2^{\circ} \mathrm{Grau}$, entre as áreas de Psicologia, Sociologia ou Didática.

A partir da criação destas duas habilitações Pré-Escola e Séries Iniciais, muitos professores da universidade passaram a direcionar seus estudos e pesquisas para uma ou outra habilitação e muitos optaram por trabalhar apenas no curso com que mais se identificava. Supomos que devido a essa característica que o corpo docente do curso de Pedagogia da FURG foi assumindo, o fim das habilitações gerou tanto desgosto entre os professores.

No ano de 1995, foi aprovada pelo Conselho de Ensino, Pesquisa e Extensão mais uma reformulação no Curso de Pedagogia na FURG, conforme expresso pela Deliberação 
$n^{\text {o }}$ 23/1995. Essa alteração determinou que a partir do ano de 1996 fosse reativa da oferta da habilitação Magistério das Matérias Pedagógicas do Ensino do Segundo Grau no turno da noite e o oferecimento da Habilitação Magistério das Matérias Pedagógicas do Ensino do Segundo Grau e Pré-Escola passasse para o turno manhã, sendo mantida a oferta Magistério das Matérias Pedagógicas do Ensino do Segundo Grau e Séries Inicias do Primeiro Grau no turno da manhã. Segundo docentes que desde essa época atuam na Pedagogia, um dos motivos que justificou tal alteração foi a dificuldade que se tinha para a realização dos estágios na Pré-Escola, pois esses precisam acontecer durante o dia, apesar dos estudantes cursarem a Pedagogia à noite.

Em 2002, as habilitações do Magistério das Matérias Pedagógicas do Ensino do Segundo Grau e Pré-Escola e do Magistério das Matérias Pedagógicas do Ensino do Segundo Grau e Séries Inicias do Primeiro Grau, passam por reformulações curriculares, que alteram além de algumas disciplinas oferecidas nos cursos o nome destes que passara a denominar-se Curso de Pedagogia - Educação Infantil e Curso de Pedagogia - Anos Iniciais do Ensino Fundamental, conforme Deliberação no 25/2002, do Conselho de Ensino, Pesquisa e Extensão, em 18 de abril de 2002. Tais alterações atenderam as orientações legais tanto da Lei de Diretrizes e Bases da Educação Nacional, como as Resoluções do Conselho Nacional de Educação, que estabeleceram as diretrizes curriculares para cursos de formação de professores. Neste período, foi mantida a oferta da habilitação Magistério das Matérias Pedagógicas do Ensino do Segundo Grau.

Em dezembro de 2003, a Universidade decidiu por não mais oferecer o Curso de Pedagogia - Habilitação: Magistério das Matérias Pedagógicas do Ensino Médio Modalidade Normal, em seu lugar no turno da noite, passou a ser ofertado o Curso de Pedagogia Anos Iniciais do Ensino Fundamental. Tal decisão passou a vigorar a partir do primeiro semestre de 2004, conforme Deliberação $n^{\circ}$ 50/2003 do Conselho de Ensino, Pesquisa e Extensão. A extinção do Curso de Pedagogia Habilitação: Magistério das Matérias Pedagógicas do Ensino Médio - Modalidade Normal foi motivada pela dificuldade de inserção dos egressos do curso no mercado de trabalho.

No ano de 2004, foi aprovada mais uma alteração curricular do Curso de Pedagogia - Educação Infantil, que, a partir de 2005, passou a oferecer 45 vagas no turno da manhã. Com relação ao Curso de Pedagogia Anos Iniciais do Ensino Fundamental, este também sofreu algumas alterações curriculares e deixou de ser oferecido no turno da manhã, ficando sua oferta apenas no turno da noite com 45 vagas.

Por fim, a última alteração curricular do Curso de Pedagogia da FURG ocorreu no ano de 2006, por ocasião da aprovação das Diretrizes Curriculares Nacionais para o Curso de Pedagogia (Resolução CNE/CP $\mathrm{n}^{\circ} 1 / 2006$ ). Com as novas diretrizes o curso teve que assumir uma nova organização, pois a legislação propunha o fim das habilitações e a formação de um pedagogo com perfil generalista. Assim, a FURG reformulou seus cursos de Pedagogia, que na época, caracterizavam-se pela formação de professores para Educação Infantil e Anos Iniciais do Ensino Fundamental em cursos específicos, propondo a criação do Curso de Pedagogia-Licenciatura.

Nesta seção do texto, procuramos evidenciar como o Curso de Pedagogia na Universidade Federal do Rio Grande - FURG foi se configurando ao longo do tempo, desde sua criação. Cabe destacar que com a oferta das habilitações para Educação Infantil (Pré-Escola) e Anos Iniciais do Ensino Fundamental (séries iniciais) criou-se uma identidade muito forte entre professores e egressos do curso para essas áreas de formação. O pertencimento a essas áreas de formação pode ser percebido pela constituição de núcleos de estudo e pesquisa que se dedicam, por exemplo, a questões relativas à alfabetização, às 
metodologias de ensino para os anos iniciais, à infância, à educação de zero a seis anos, entre outras.

Conforme já explicitado, na época das habilitações, havia docentes que atuavam em apenas um dos cursos devido à sua afinidade com a área e ao seu campo de estudo e formação. Da mesma forma que ocorria com os docentes, os estudantes desses cursos ingressavam pela vontade e/ou afinidade em relação ao trabalho com crianças pequenas, no caso da Educação Infantil, ou do trabalho com crianças maiores, desenvolvendo práticas mais escolarizadas. Os egressos desses cursos saíam com uma consistente formação na área de formação e uma grande identificação com o futuro campo de atuação. Consideramos que, nos últimos anos, a alteração que propôs a criação do Curso de Pedagogia - Educação Infantil e o Curso de Pedagogia - Anos Inicias foi a de maior significado na formação do pedagogo na FURG.

Com as novas diretrizes nacionais para o Curso de Pedagogia, os cursos de Pedagogia no país tiverem que encerrar a oferta de habilitações e passaram a oferecer única opção.

\section{O PROJETO PEDAGÓGICO DO CURSO DE PEDAGOGIA-LICENCIATURA DA FURG}

O projeto do Curso de Pedagogia - Licenciatura da FURG foi elaborado em 2006, por um grupo composto por 10 professores que compunham a Comissão de Curso de Pedagogia. O documento foi organizado a partir dos seguintes aspectos: histórico e justificativa; caracterização do Curso; perfil do Profissional; objetivos; procedimentos metodológicos; carga horária; plano de implementação das disciplinas; ementas das disciplinas; quadro de sequência lógica; e, recomendações.

No que se refere ao histórico e à justificativa do curso, o projeto do curso evidencia sua conformidade com os objetivos e intencionalidades expressos no Projeto PolíticoPedagógico e no Plano de Desenvolvimento Institucional da FURG. O curso de Pedagogia em seu projeto compromete-se com a democratização do acesso ao ensino de graduação, bem como com a vocação institucional que preconiza a indissociabilidade entre ensino, a pesquisa e a extensão para o desenvolvimento de ações voltadas para o ecossistema costeiro (FURG, 2006).

Além disso, o projeto do curso salienta que as reformulações pelas quais o Curso de Pedagogia vem passando acompanham o debate nacional acerca dos rumos que a formação do pedagogo vem assumindo no país. Desse modo, há o relato de que a Comissão de Curso de Pedagogia (ComCur de Pedagogia) procura promover discussões no âmbito da instituição principalmente quando são promulgadas regulamentações legais sobre a formação de professores. Segundo o projeto do curso, tendo em vista a aprovação da Resolução CNE/CP n ${ }^{\circ}$ 1/2006, a Comissão de Curso de Pedagogia desenvolveu várias atividades, entre elas um debate envolvendo propostas curriculares de outras instituições de ensino superior; um encontro interinstitucional para troca de experiências; estudo dos documentos das Diretrizes Curriculares Nacionais; consulta a professores e acadêmicos envolvidos com o Curso de Pedagogia; reunião com os professores que atuam no curso.

Com isso, o Projeto Pedagógico justifica a criação do Curso de PedagogiaLicenciatura principalmente em função das exigências legais, mas também afirma que é pautado nas "perspectivas de formação docente para este milênio e pelas necessidades apontadas pelos acadêmicos do curso" (2006, p.3). Assim, o desenho curricular proposto toma como base as constatações dos estudos apresentados acerca da formação docente e a problemática do ensino e da aprendizagem na Educação Infantil e nos Anos Iniciais do 
Ensino Fundamental, prioritariamente, mas também na Gestão Escolar. Assim, prevê a interação entre as disciplinas de cada Núcleo e a contextualização dos conhecimentos trabalhados nas mesmas com o cotidiano da ação docente.

Neste novo desenho a ComCur de Pedagogia acredita ser também de grande relevância na formação do profissional que atua neste nível de ensino, os conhecimentos acerca da Educação de Jovens e Adultos, principalmente no que se refere à alfabetização, pois este docente também poderá ser solicitado a atuar nos programas da EJA. (Projeto Pedagógico do Curso de Pedagogia-Licenciatura, 2006, p. 6)

O desenho curricular proposto vai ao encontro do estabelecido nas Diretrizes Curriculares, pois com a extinção das habilitações pelo artigo 10, os cursos de Pedagogia deverão assumir prioritariamente em seus currículos a formação para a docência na Educação Infantil e nos Anos Iniciais do Ensino Fundamental, além de envolver outras áreas no âmbito da formação do pedagogo.

O curso foi proposto com a oferta de uma turma com 45 estudantes no turno da manhã e outra no turno da noite, tendo como perfil profissional exatamente o estabelecido no artigo $4^{\circ}$ da Resolução CNE/CP n ${ }^{\circ} 1 / 2006$, ou seja:

$\mathrm{O}$ curso de Licenciatura em Pedagogia destina-se à formação de professores para exercer funções de magistério na Educação Infantil e nos anos iniciais do Ensino Fundamental, nos cursos de Ensino Médio, na modalidade Normal, de Educação Profissional na área de serviços e apoio escolar e em outras áreas nas quais sejam previstos conhecimentos pedagógicos.

Parágrafo único. As atividades docentes também compreendem participação na organização e gestão de sistemas e instituições de ensino, englobando:

I - planejamento, execução, coordenação, acompanhamento e avaliação de tarefas próprias do setor da Educação;

II - planejamento, execução, coordenação, acompanhamento e avaliação de projetos e experiências educativas não-escolares;

III - produção e difusão do conhecimento científico-tecnológico do campo educacional, em contextos escolares e não-escolares. (BRASIL, 2006, p.1)

Considerando o perfil desejado, o objetivo do curso consiste em

Formar o Pedagogo para a docência na Educação Infantil e nos Anos Iniciais do Ensino Fundamental, nos Cursos de Ensino Médio, na modalidade Normal, e em cursos de Educação Profissional na área de serviços e apoio escolar e em outras áreas nas quais sejam previstos conhecimentos pedagógicos, buscando ainda desenvolver neste profissional, capacidades de gestão e de coordenação pedagógica para atuar em espaços escolares e não escolares. $\mathrm{O}$ curso propõe, também, contemplar a discussão sobre Educação de Jovens e Adultos a fim de possibilitar ao Pedagogo uma visão mais abrangente sobre o processo educacional brasileiro" (FURG - Projeto Pedagógico do Curso de Pedagogia-Licenciatura, 2006, p. 8).

Apesar do enfoque principal do curso estar na formação para a docência na Educação Infantil e nos Anos Iniciais do Ensino Fundamental, pelo perfil profissional e 
pelo objetivo proposto fica evidenciado que a formação acaba assumindo um caráter bastante generalista, seguindo o expresso pelas Diretrizes Curriculares.

O currículo do curso está organizado a partir de 4 núcleos, compostos por disciplinas, seguindo as orientações do artigo $6^{\circ}$ da Resolução $n^{\circ} 1 / 2006$. Abaixo apresentamos o modo como a FURG estabeleceu os núcleos e disciplinas:

3. O primeiro núcleo é de Estudos Básicos e apresenta a seguinte ementa "Situa o ser social no tempo e no espaço presente, diante de questões relevantes da educação, estabelecendo articulações com o passado e o futuro. Favorece o conhecimento da realidade em que se insere o processo educativo. Fomenta reflexões que possibilitem pensar proposições e perspectivas educativas desde o começo do curso" (FURG Projeto Pedagógico do Curso de Pedagogia-Licenciatura, 2006, p. 12). Fazem parte deste núcleo as disciplinas de Filosofia da Educação; Sociologia da Educação; Psicologia da Educação; História da Educação Brasileira; Didática I - Pedagogia; Produção Textual e Infâncias; e, Culturas e Educação. Todas as disciplinas desse núcleo são anuais.

4. O segundo núcleo do curso é denominado Núcleo de Aprofundamento e Diversificação de Estudos, que "considera a atividade docente como um trabalho inserido num contexto de mundo e num cotidiano escolar. Analisa este cotidiano tomando por referência as práticas e metodologias educativas realizadas na Educação Infantil, nos Anos Iniciais do Ensino Fundamental, na Educação de Jovens e Adultos e na Gestão Educacional. Retoma as discussões contidas no Núcleo de Estudos Básicos articulando com o cotidiano pedagógico" (FURG - Projeto Pedagógico do Curso de Pedagogia-Licenciatura, 2006, p. 15). Entre as disciplinas que compõem este núcleo destacam-se as disciplinas anuais de Fundamentos e Metodologia da Educação Infantil I; Metodologia do Ensino de Ciências Sociais; Políticas Públicas de Educação; e Didática II - Pedagogia. Entre as disciplinas semestrais têm as oferecidas no $3^{\circ}$ período do curso, quais sejam: Psicologia da Infância e da Adolescência; Educação de Jovens e Adultos; Corporeidade e Movimento; e, Arte Linguagem e Educação; e as oferecidas no $4^{\circ}$ período do curso, entre elas Psicolinguística; Jogos, Brinquedos e Culturas; Fundamentos e Metodologia da Pesquisa.

5. O terceiro núcleo que compõe o currículo do curso é o de Estudos Integradores, o qual "Discute as experiências na Educação Infantil e nos Anos Iniciais do Ensino Fundamental no Brasil, considerando a real situação deste nível de ensino através do seu histórico. Ressalta os desafios atuais no sentido de gestar proposições educacionais" (FURG - Projeto Pedagógico do Curso de Pedagogia-Licenciatura, 2006, p. 19). Este núcleo é composto pelas disciplinas de História e Metodologia da Alfabetização I; História e Metodologia da Alfabetização II; Metodologia do Ensino da Matemática; Metodologia do Ensino da Língua Portuguesa; Metodologia do Ensino das Ciências Naturais; Fundamentos e Metodologia da Educação Infantil II; Estudos Sócio-Antropológicos da Infância e da Juventude; Gestão Educacional; Cotidiano na Educação Infantil; e, Estágio. Destas disciplinas apenas as de História e Metodologia da Alfabetização são semestrais.

6. O quarto núcleo é o Núcleo de Proposições e Perspectivas Educativas, o qual "discute propostas educativas a partir das reflexões e estudos feitos nos anos anteriores e analisa o fazer pedagógico. Propõe perspectivas de atuação do pedagogo, sua inserção no contexto de mundo, no cotidiano educacional e no trabalho docente, configurandose em projetos educacionais" (FURG- Projeto Pedagógico do Curso de PedagogiaLicenciatura, 2006, p. 24). Este núcleo está organizado em disciplinas anuais como 
Psicologia da Educação dos Portadores de Necessidades Especiais; Ética e Educação; Libras; Formação Docente; e disciplinas semestrais oferecidas no $7^{\circ}$ período as de Literatura Infanto-Juvenil; Oficina de Brinquedos; Estágio na Educação Infantil; e uma disciplina optativa; e no $8^{\circ}$ período as disciplinas de Trabalho de Conclusão de curso; Tópicos Específicos da Educação Infantil; Estágio nos anos iniciais; e mais uma disciplina optativa ${ }^{13}$.

O curso foi proposto inicialmente com 3355 horas a serem integralizadas em 4 anos. Porém, no ano de 2008, a Comissão de Curso realizou uma alteração curricular no último ano do curso e reduziu a carga horária do curso para 3265 horas. A alteração proposta excluiu do currículo a disciplina de Formação Docente, passou para semestral as disciplinas de Psicologia da Educação dos Portadores de Necessidades Especiais e Ética e Educação e passou a disciplina de Tópicos Específicos da Educação Infantil para o $7^{\circ}$ período e a disciplina de Estágio na Educação Infantil para o $8^{\circ}$ período. Esta reformulação foi provocada pela preocupação que o grupo de docentes juntamente com a coordenação do curso tiveram com relação ao último ano do curso, que inicialmente previa que os estudantes deveriam realizar os estágios da Educação Infantil e dos anos iniciais do Ensino Fundamental paralelamente com seis disciplinas.

Ao término do ano de 2010, com a vivência do quarto ano do curso e a conclusão da primeira turma, a Coordenação do Curso aprovou mais uma alteração curricular. As alterações realizadas excluíram do currículo as disciplinas Estudos Sócio-Antropológicos da Infância e da Juventude; Ética e Educação; Oficina de Brinquedos; Corporeidade e Movimento; e, a obrigatoriedade de uma das optativas, aumentou a carga-horária das disciplinas de Estágio e Trabalho de Conclusão de Curso de 60 para 120horas, e, incluiu no currículo as disciplinas Currículo dos anos iniciais do Ensino Fundamental; Tópicos Especiais dos anos iniciais do Ensino Fundamental; e Tópicos Especiais da Educação de Jovens e Adultos.

Essas últimas alterações foram motivadas principalmente pela manifestação dos alunos que indicavam a necessidade de disciplinas que evidenciasse mais o trabalho pedagógico nos anos iniciais de maneira articulada, a partir de uma perspectiva de currículo integrado.

\section{DA FORMAÇÃO ESPECÍFICA PARA A FORMAÇÃO GENERALISTA: IDENTIDADES EM TRANSFORMAÇÃO}

Conforme fomos discutindo o Curso de Pedagogia da FURG, ao buscar a adequação do seu currículo às Diretrizes Curriculares para o Curso de Pedagogia aprovadas em 2006, extinguiu as habilitações para Educação Infantil e Anos Iniciais do Ensino Fundamental e passou a formar o licenciando em Pedagogia, de modo a tornar-se apto para "exercer funções de magistério na Educação Infantil, nos Anos Iniciais do Ensino Fundamental, na Educação de Jovens e Adultos e na Área de Serviços e Apoio Escolar, bem como em outras áreas nas quais sejam previstos conhecimentos pedagógicos" (BRASIL, 2006).

A concepção da docência como "base comum nacional", desde meados da década de 1980 já estava presente nos cursos de Pedagogia da FURG, que buscavam acompanhar o debate nacional da época. Como podemos verificar no Curso de Pedagogia - Educação Infantil a concepção do curso deixava bem claro o foco na docência ao expressar:

O Curso de Pedagogia Educação Infantil tem por base a formação do profissional da educação, ou seja, a docência. Com este propósito, o 
currículo deste curso está organizado a fim de oportunizar aos alunos a vivência no espaço educativo. (FURG, 2004a, p. 10)

Da mesma forma, no Projeto Pedagógico do Curso de Pedagogia - Anos Iniciais também evidencia sua concepção na docência, verificada no trecho "O Curso de Pedagogia Anos Iniciais do Ensino Fundamental tem por base a formação do profissional da educação, ou seja, a docência" (FURG, 2004b, p. 10).

É possível perceber que a docência constitui um aspecto central para identidade dos cursos de Pedagogia na FURG. Consideramos que "a identidade de todos e qualquer ser empírico depende da época considerada, do ponto de vista adotado" e que "são modos de identificação, historicamente variáveis"(DUBAR, 2009, p. 13), assim, entendemos que neste momento de transição do Projeto do Curso de Pedagogia foi importante investigar que novos sentimentos de pertencimento podem estar sendo construídos.

Analisando comparativamente os Projetos Pedagógicos dos cursos de Pedagogia da $\mathrm{FURG}^{14}$, foi possível perceber que, a fim de adequar a formação para a docência da Educação Infantil e dos Anos Iniciais em um mesmo curso foi preciso reduzir a carga horária de algumas disciplinas para dar conta dessa dupla formação em um mesmo currículo. Os cursos de Pedagogia Educação Infantil e anos iniciais possuíam uma carga horária total de 2840 horas; já o atual Curso de Pedagogia estabelece a carga horária total em 3265 horas. Ainda que tenha ocorrido o aumento da carga horária, não seria possível manter a formação para os dois níveis de ensino com a mesma carga horária antes estipulada, até mesmo porque outros aspectos se somam à formação do pedagogo, como, por exemplo, a formação do gestor educacional.

Acreditamos que o maior impacto das alterações realizadas no Curso de Pedagogia é evidenciado nas disciplinas de Estágio, que tiveram diminuição da sua carga horária passando de 400 para 300 horas. Anteriormente era previsto no PPP dos cursos 4 disciplinas semestrais de Estágio que propunham a inserção no cotidiano educativo específico da Educação Infantil ou dos anos iniciais. Atualmente, o Curso de Pedagogia da FURG prevê apenas três disciplinas de estágio, sendo uma anual, que se divide entre a inserção no cotidiano da Educação Infantil e dos Anos Iniciais, e duas disciplinas oferecidas no último semestre do curso, que preveem, respectivamente, o estágio de regência na Educação Infantil e a regência nos Anos Iniciais.

Cabe dizer, que nos cursos de Pedagogia - Educação Infantil e Pedagogia - Anos Iniciais, as disciplinas de Estágio VI, nas quais os estudantes desenvolviam atividades docentes em uma turma possuía uma carga horária de 225 horas; já no curso novo, o estágio de regência de turma possui, cada um, a carga horária de 120 horas. Esse aspecto reduz significativamente o tempo da experiência docente em sala de aula, o que certamente interferirá na construção das identidades profissionais docentes.

Outro aspecto que se faz importante destacar é que com a Resolução CNE/CP $\mathrm{n}^{\circ}$ 1/2006, a finalidade do Curso de Pedagogia foi definida no artigo segundo, que estabeleceu: "aplica-se à formação inicial para o exercício da docência na Educação Infantil e nos anos iniciais do Ensino Fundamental, nos cursos de Ensino Médio, na modalidade Normal, e em cursos de Educação Profissional na área de serviços e apoio escolar, bem como em outras áreas nas quais sejam previstos conhecimentos pedagógicos". (BRASIL, 2006) Essa formulação deixa claro que o curso se constituirá como uma licenciatura, vocacionado à formação do professor. No entanto, essa compreensão não restringe a docência às atividades pedagógicas em sala de aula. O egresso da Pedagogia deverá estar preparado para desenvolver outros trabalhos de natureza educativa, aspecto que fica expresso no artigo $4^{\circ}$ das Diretrizes, o qual apresenta que as atividades docentes envolvem a gestão e a organização a partir do planejamento, da execução, da coordenação, 
do acompanhamento, da avaliação de sistemas e instituições de ensino formais e não formais, bem como ações de produção e difusão do conhecimento científico-tecnológico do campo educacional.

Assim, no Projeto Político-Pedagógico do Curso de Pedagogia da FURG, estão previstas disciplinas de Políticas Públicas de Educação, Gestão Educacional, Psicologia dos Portadores de Necessidades Especiais, Língua Brasileira de Sinais, Educação de Jovens e Adultos, Fundamentos e Metodologia da Pesquisa em Educação, que buscam dar conta da concepção alargada de docência, que vai além da formação de professores da infância.

Quando a formação no Curso de Pedagogia era específica para uma ou outra área, podia ser considerado que a identificação com o campo profissional era anunciada desde o ingresso no curso. Todas as ações eram pensadas para a formação daquele profissional em específico: professor da Educação Infantil ou dos Anos Iniciais. A atual configuração do Curso de Pedagogia abre um leque de possibilidades de atuação profissional, conforme evidenciado acima, mas possui como eixo comum a ideia da docência; no entanto, apesar desse eixo, não fica claro aos estudantes e muitas vezes aos próprios professores do curso a que campo de atuação pertence.

Essa perspectiva na formação de pedagogos está ancorada no quadro das políticas educacionais brasileiras que, desde a década de 1990, vem promovendo um processo de reforma política. As mudanças engendradas pelo Estado brasileiro na área educacional configuram-se como uma resposta às transformações do mundo produtivo, para o qual características como polivalência dos trabalhadores, reestruturação das ocupações, flexibilização da produção, precisam estender-se à esfera educacional como uma das condições para sua própria existência social. A formação do licenciado em Pedagogia está sendo pensada nestes moldes e levam a uma formação generalista deste profissional (VIEIRA, 2007, 2012; DURLI, 2007; CANAN, 2009; EVANGELISTA, 2008, 2009; SOARES, 2010).

Scheibe, ao analisar as propostas de diretrizes curriculares para o Curso de Pedagogia destaca que existe "uma importante diferença entre a proposta de diretrizes de 1999 e a atual definição para o Curso de Pedagogia: a primeira definia uma estrutura curricular geral possibilitadora de opções e verticalizações de formação; a atual definição é mais generalista e panorâmica" (2006, p. 6). Concordando com a autora, questionamos que novos sentimentos de pertencimento ao campo da Pedagogia essa formação ampliada tem provocado.

Com o fim das habilitações, fica estabelecida uma formação generalista, perceptível pela abertura oferecida pelas diretrizes no que tange ao raio de atuação do licenciado em Pedagogia, sugerindo, ademais, uma variedade de possibilidades para que percursos e trajetórias individuais sejam possíveis. Por mais, que se saiba que a identidade possui um caráter individual e outro coletivo, é preciso que se tenha uma identificação com a formação para que se produza saberes significativos, que promovam comprometimento com o campo profissional e o meio sócio-ambiental.

Dubar afirma que "a identidade não é o que permanece necessariamente "idêntico", mas o resultado de uma "identificação" contingente"( 2009, p. 13). Ainda citando Dubar, cabe dizer que "a identidade é o pertencimento comum" (2009, p.13).O Curso de Pedagogia, como um espaço de formação de professores, é promotor dessa identificação; nele professores e futuros professores produzindo o que Tardif (2002) chamou de saberes profissionais e disciplinares e vão construindo uma identidade que é própria, mas também coletiva. 
No caso em tela, em que analisamos o Curso de Pedagogia da FURG, entendemos que a nova organização curricular do curso tem provocado o que Dubar (2009) chama de uma crise de identidade. Essa ideia está ancorada nas mudanças sociais que estão articuladas à nova configuração das forças produtivas, e questiona as relações sociais que levam a perda do vínculo social. Considero que com a formação proposta pelas novas Diretrizes do curso, não fica claro aos estudantes, muitas vezes, qual o campo de atuação da Pedagogia, aspecto esse que fragiliza o estabelecimento de um sentimento de pertencimento à área de formação.

O projeto pedagógico do curso não deixa explícito qual a identidade do curso de Pedagogia da FURG, no entanto ao analisar o currículo, vamos destacando a docência como eixo central da formação do Pedagogo na FURG e uma forte ênfase na formação do professor da Educação Infantil e dos anos iniciais do Ensino Fundamental. Nesse sentido, acreditamos que é na direção da formação de professores da infância ${ }^{15}$ que caminhará o pertencimento dos estudantes na FURG, já que as demais áreas de atuação do pedagogo estão presentes no curso de Pedagogia da FURG de maneira muito superficial, como é o caso da gestão escolar que é tratada em apenas uma disciplina.

\section{Referências}

ALMEIDA, Cleuza Ivety Ribes de. Engenharias e Ciências Exatas. In: ALVES, Francisco das Neves (orgs.) Fundação Universidade Federal do Rio Grande: 35 anos a serviço da comunidade. Rio Grande: Editora da FURG, 2004.

ALVES, Francisco das Neves. Ciências Humanas. In: ALVES, Francisco das Neves (orgs.) Fundação Universidade Federal do Rio Grande: 35 anos a serviço da comunidade. Rio Grande: Editora da FURG, 2004.

BRASIL. Lei $n^{\circ}$ 9.394, de 20 de dezembro de 1996. Estabelece as diretrizes e bases da educação nacional.

.CONSELHO NACIONAL DE EDUCAÇÃO. Resolução nº 1/2002. Institui

Diretrizes Curriculares Nacionais para a Formação de Professores da Educação Básica, em nível superior, curso de licenciatura, de graduação plena. Fevereiro de 2002a.

.CONSELHO NACIONAL DE EDUCAÇÃO. Resolução nº 2/2002. Institui a duração e a carga horária dos cursos de licenciatura, de graduação plena, de formação de professores da Educação Básica em nível Superior. Fevereiro de 2002b.

CONSELHO NACIONAL DE EDUCAÇÃO. Resolução 1/2006. Institui Diretrizes Curriculares Nacionais para o Curso de Graduação em Pedagogia, licenciatura. Maio de 2006b. Disponível em <http://mec.gov.br/cne> Acesso em 2 de junho de 2006.

CANAN, Silvia Regina. Diretrizes Curriculares Nacionais para Formação de Professores da Educação Básica: tensões e limites entre o específico e o pedagógico na formação docente. 2009. Tese de Doutorado. Programa de Pós-graduação em Educação. Universidade do Vale do Rio dos Sinos. São Leopoldo, RS, 2009. 
COUSIN, Claudia da Silva. Pertencer ao navegar, agir e narrar: a formação de educadores ambientais. Tese de Doutorado. Programa de Pós-graduação em Educação Ambiental da Universidade Federal do Rio Grande - FURG. Rio Grande 2010.

DUBAR, Claude. A Socialização: a construção das identidades sociais e profissionais. São Paulo: Martins Fontes, 2005.

. A Crise das Identidades: a interpretação de uma mutação. São Paulo: Editora da Universidade de São Paulo, 2009.

DURLI, Zenilde. O processo de construção das Diretrizes Curriculares Nacionais para o Curso de Pedagogia: concepções em disputa. 2007. Tese de Doutorado. Programa de Pós-Graduação em Educação - Centro de Ciências da Educação, Universidade Federal de Santa Catarina, Florianópolis,SC, 2007.

EVANGELISTA, Olinda. Conhecimento e Diretrizes curriculares para o curso de Pedagogia no Brasil. In: Perspectiva, Florianópolis, v. 26, n.2, 551-570, jul./dez.2008.

EVANGELISTA, O. e TRICHES, J. Diretrizes Curriculares Nacionais para o Curso de Pedagogia: Docência, gestão e pesquisa. In: ANPED Sul, Itajaí, 2008.

Docência, Gestão e Pesquisa nas Diretrizes Curriculares Nacionais para o Curso de Pedagogia. In: Revista Brasileira de Formação de Professores - RBFP.vol. 1, $\mathrm{n}^{\circ}$ 2, p. 178-203, setembro de 2009.

EVANGELISTA, Olinda; MORAES, Maria Célia Marcondes; SHIROMA, Eneida Oto Política Educacional. Rio de Janeiro, DP\&A, 2003.

FURG. CONSELHO DE ENSINO, PESQUISA e EXTENSÃO. Deliberação $n^{\circ}$ 17/1986. Dispõe sobre a aprovação da estrutura curricular das novas habilitações do Curso de Pedagogia.Mimeo.

CONSELHO DE ENSINO, PESQUISA e EXTENSÃO. Deliberação $n^{\circ}$ 23/1995. Dispõe sobre alteração curricular do Curso de Pedagogia.Mimeo.

CONSELHO DE ENSINO, PESQUISA e EXTENSÃO. Deliberação $n^{\circ}$ 25/2002. Dispõe sobre alteração curricular nos Cursos de Pedagogia. Mimeo.

CONSELHO DE ENSINO, PESQUISA e EXTENSÃO. Deliberação $n^{\circ}$ 50/2003. Dispõe sobre o Plano de último oferecimento das disciplinas do Curso de Pedagogia Habilitação Magistério do Ensino Médio e Implantação do Curso de Pedagogia Anos Iniciais do Ensino Fundamental - Noite. Mimeo.

.Projeto Político-Pedagógico do Curso de Pedagogia - Educação Infantil. 2004a. Mimeo.

Projeto Político-Pedagógico do Curso de Pedagogia - Anos Iniciais. 2004a.

Mimeo.

Projeto Político-Pedagógico do Curso de Pedagogia - Licenciatura. 2006.

Mimeo. 
MEDEIROS, Ivone Regina. CURSO DE PEDAGOGIA DA FURG: um estudo sobre a influência da formação na atuação da profissional egressa. Dissertação de Mestrado.1999. Programa de Pós-Graduação em Educação da Universidade Federal de Pelotas. Pelotas, RS, 1999.

NUNES, Claudio Omar Iahnke. Ciências Sociais e Aplicadas. In: ALVES, Francisco das Neves (orgs.) Fundação Universidade Federal do Rio Grande: 35 anos a serviço da comunidade. Rio Grande: Editora da FURG, 2004.

RIBES, Eva Lizety, CESTARI, Maria Luísa, MIRANDA, Olga. Proposta de ajustamento da oferta do Curso de Pedagogia (estudos prévios para discussão).Rio Grande: FURG, 1995 a , mimeo.

SÁ, Laís Mourão. Pertencimento. In: FERRARO JÚNIOR, L. A. (Org.). Encontros e caminhos: formação de educadoras (es) ambientais e coletivos educadores. Brasília: MMA, Diretoria de Educação Ambiental, 2005, p. 245 - 256.

SCHEIBE, Leda. O curso de Pedagogia no embate entre concepções de formação. In: GUIMARÃES, Valter Soares. Formar para o mercado ou para a autonomia? o papel da universidade. Campinas, SP: Papirus, 2006.

SHIROMA, Eneida Otto; CAMPOS, Roselaine Fátima; GARCIA, Rosalba. Decifrar textos para compreender a política: subsídios teórico-metodológicos para análise de documentos. Perspectiva, Florianópolis, v. 23, n. 2, p. 427-446, jul./dez. 2005.

SOARES, Solange Toldo. O Processo de Construção das Diretrizes Curriculares Nacionais para o Curso de Pedagogia no Brasil (1996-2006): Ambiguidades nas Propostas de Formação do Pedagogo. 2010. Dissertação de Mestrado. Programa de PósGraduação em Educação da Universidade Federal do Paraná. Curitiba,PR, 2010.

VIEIRA, Suzane da Rocha. Diretrizes Curriculares para o curso de Pedagogia: pedagogo, docente ou professor? 2007. Dissertação de Mestrado. Programa de Pós-Graduação em Educação. Centro de Ciências da Educação. Universidade Federal de Santa Catariana. Florianópolis, SC, 2007.

. O Sentimento de Pertencimento na formação do Pedagogo: o curso de Pedagogia da FURG no contexto das novas diretrizes curriculares. 2012. Tese de Doutorado. Programa de Pós-Graduação em Educação Ambiental. Instituto de Educação. Universidade Federal do Rio Grande. Rio Grande, RS, 2012.

TARDIF, Maurice. Saberes Docentes e Formação Profissional. Petrópolis, RJ: Vozes, 2002.

Recebido em agosto-12

Aprovado em fevereiro-13 


\section{Notas}

${ }^{1}$ Professora Adjunta do Instituto de Educação da Universidade Federal do Rio Grande - FURG. Mestre em Educação - UFSC e doutora em Educação Ambiental - FURG. Pesquisadora do Núcleo de Estudo e Pesquisa em Educação da Infância.suzanevieira@furg.br

${ }^{2}$ Professora Associada do Instituto de Educação da Universidade Federal do Rio Grande - FURG. Mestre em Educação e doutora em Educação - PUC-RS. Pesquisadora do Núcleo de Estudo e Pesquisa em Educação da Infância e do Núcleo de Estudos em Educação de Jovens e Adultos e em Alfabetização. cleuzadias@ furg.br

${ }^{3}$ Professora Adjunda do Instituto de Educação da Universidade Federal do Rio Grande - FURG. Mestre em Educação e doutora em Educação - PUC-RS. Pesquisadora do Núcleo de Estudos em Educação de Jovens e Adultos e em Alfabetização. vanise@ vetorial.net

${ }^{4}$ A Universidade Federal do Rio Grande - FURG está situada no município do Rio Grande, localizado na região sul do Estado do Rio Grande do Sul.

${ }^{5} \mathrm{O}$ funcionamento da Escola de Engenharia Industrial foi autorizado em 24 de maio de 1955, pelo Decreto $\mathrm{n}^{\circ}$ 37.378 .

${ }^{6} \mathrm{O}$ funcionamento da Faculdade de Ciências Políticas e Econômicas foi autorizado em 24 de abril de 1958, pelo Decreto 43.563.

7 O município de Pelotas fica localizado cerca de 64km do município do Rio Grande no Rio Grande do Sul - Brasil.

${ }^{8}$ No ano de 1964 foi autorizado o funcionamento do Curso de Letras, com habilitação para inglês e francês.

${ }^{9}$ No ano de 1966 foi autorizado o funcionamento do curso de Matemática.

${ }^{10}$ Os cursos de Ciências e Estudos Sociais foram autorizados para funcionamento no ano de 1968.

${ }^{11}$ Após a LDB o curso de Magistério passou a denominar-se Curso Normal.

12 Os cursos de Pedagogia oferecidos pela FURG em sua trajetória foram: Pedagogia - Habilitação Magistério; Pedagogia - Habilitação Magistério e Supervisão Escolar; Pedagogia - Habilitação Magistério e Administração Escolar, Pedagogia - Habilitação Magistério e Orientação Educacional; Pedagogia Habilitação Supervisão Escolar; Pedagogia - Habilitação Administração Escolar; Pedagogia - Habilitação Orientação Educacional; Pedagogia - Habilitação Inspeção Escolar; Pedagogia - Habilitação Magistério e Inspeção Escolar; Pedagogia - Habilitação Magistério e Pré-Escola; Pedagogia - Habilitação Magistério e Séries Iniciais; Pedagogia - Habilitação Anos Iniciais do Ensino Fundamental; Pedagogia - Habilitação Educação Infantil; Pedagogia - Licenciatura.

13 Entre as disciplinas optativas são oferecidas as seguintes: Educação a Distância; Questões Atuais da História da Educação Brasileira; Abordagens Didáticas em Educação de Jovens e Adultos; Educação Popular e Movimentos Sociais; Educação e Trabalho; Educação Profissional de Jovens e Adultos; Mídias e Educação; e Psicopedagogia do Adulto.

${ }^{14}$ Pedagogia - Educação Infantil, Pedagogia - Anos Iniciais e Pedagogia - Licenciatura.

${ }^{15}$ Entendemos que professores da infância são aqueles que trabalham com crianças de 0 a 12 anos. 